\title{
PERMANENT INCOME, LIQUIDITY, AND EXPENDITURE \\ ON AUTOMOBILES: EVIDENCE FROM PANEL DATA
}

\author{
Ben S. Benanke \\ Working Paper No. 756 \\ NATIONAL BUREAU OF ECONOMIC RESEARCH \\ 1050 Massachusetts Avenue \\ Cambridge MA 02138 \\ September 1981
}

Partial support was provided by the National Science Foundation. Jon Zucker gave excellent research assistance and wrote much of the data appendix. The author would like to thank George Fenn and Robert Hall for comments. The research reported here is part of the NBER's research program in Economic Fluctuations. Any opinions expressed are those of the author and not those of the National Bureau of Economic Research. 


\author{
Permanent Income, Liquidity, and \\ Expenditure on Automobiles: \\ Evidence from Panel Data
}

\begin{abstract}
Several recent papers have tested the permanent income-cumrational expectations hypothesis using data on nondurable or semidurable consumption. We show how this approach can be extended to the case of durables. An application to panel data on automobile expenditures reveals no evidence against the permanent income hypothesis. This result is unchanged in subsamples segregated by family holdings of liquid assets.
\end{abstract}

Ben Bernanke Assistant Professor of Economics Graduate School of Business Stanford University Stanford, California 94305

(415) 497-2763 


\section{Introduction}

The validity of the permanent income-life cycle hypothesis (PIH) as an explanation of consumer spending is an important issue in macroeconomics. ' Since this hypothesis was posed (separately) by Friedman (1957) and by Modigliani ${ }^{2}$, it has been frequently put to empirical test. ${ }^{3}$ Evidence both pro and con has been advanced.

Recently, this question has been illuminated by the realization that the hypothesis of rational expectations, in conjunction with the $\mathrm{PIH}$, imposes strong restrictions on the stochastic properties of consumption conditional on income. In pioneering articles, Hall (1978) and Sargent (1978) used these restrictions to test the joint rational expectations - permanent income hypothesis in the U.S. time series data. Flavin (forthcoming) has shown that, properly interpreted, the Hall and Sargent papers concur in rejecting the joint hypothesis.

Noting the relatively low power of time series tests, Hall and Mishkin (forthcoming) followed by applying these methods (and several innovations) in panel data. ${ }^{4}$ The results of their analysis of the relation of food consumption to income change were ambiguous; the PIH could not be clearly accepted or rejected.

One feature of this recent research has been the small amount of attention paid to the durables component of consumer expenditure: of the papers mentioned, only Sargent's does not completely eliminate durables from the measure of consumption. The reason for this neglect is that the theory, as developed, is a predictor of actual consumption; what is observed, however, is not consumption but expenditure. The 
distinction between the time of buying and the time of using being much less important for nondurables than for durables, it is the former component that has been the focus of the empirical applications.

It would seem that, in the exclusion of durables, an important and interesting part of the story has been left out. The durables component of expenditure is large, the most volatile, and the most cyclically sensitive. Further, if the PIH fails in a quantitatively important way, it is most likely to be revealed in the pattern of durables purchases. For example, as Mishkin (1976) has pointed out, durables (automobiles in particular) are large, primarily debt-financed illiquid assets; moreover, expenditures on durables are more easily rescheduled than expenditures on nondurables. Thus, durables purchases should be relatively more sensitive to liquidity constraints or imperfections in the consumer loan market -- the most plausible sources of failure of the PIH. 5

This paper attempts to fill the lacuna by testing the joint rational expectations and permanent income hypothesis for the case of automobile expenditures. An effective test is permitted by the availability of panel data which record the incomes and car expenditures of 1434 families over four years. As a bonus, the data also include family holdings of liquid assets for each year. This permits a simple test of Mishkin's "liquidity hypothesis," a principal opposing view to the strict PIH.

The results of this study differ rather sharply with those of previous papers, especially the work using time series. We find no 
evidence that liquidity constraints or capital market imperfections are important in even the timing of family car purchases. The response of expenditure to transitory income changes is as predicted by the permanent income model.

The plan of the paper is as follows. Part 2 describes the model to be estimated. Part 3 outlines the estimation procedure. Results are reported in part 4. Part 5 discusses Monte Carlo simulations that tested the robustness of the estimates to specification error. Part 6 concludes. 


\section{Automobile Expenditures and Revisions to Permanent Income}

This section presents a model of the response of family automobile purchases and sales to new information about family income. The basic approach is the same as that of Hall and Mishkin's innovative study, to which the reader is referred for additional motivation and clarification.

Let us begin by assuming that families base their consumption plans on their rationally expected level of permanent income. As usual, "permanent income" $\left(Y_{t}^{P}\right)$ is defined (relative to current-period information) as the flow of income which, if sustained at a constant level for the rest of the family's life, would just exhaust expected earnings and wealth.

An immediate problem is that permanent income is unobservable by the econometrician. In many previous studies, both of automobiles and other consumer goods, permanent income has been proxied for by some weighted average of recent actual incomes. However, as Muth (1960) and Lucas (1976) have shown, the validity of this procedure depends intimately on the stochastic process generating income; in general, using a finite-lag average as a proxy is highly restrictive. Accordingly, the income process should be explicitly modelled.

We will follow Hall-Mishkin in representing the family's total disposable income in year $t, \tilde{Y}_{t}$, as being comprised of three parts (which we assume that the family can distinguish). 6

These are

1. the deterministic component, $\overline{\mathrm{Y}}_{t}$. This is the pattern of lifetime income that can be projected from the basic demographic 
characteristics of the family (e.g., age of the head, occupation, family size). We assume that $\overline{\mathrm{Y}}_{t}$ is fixed and known in advance. 7

2. the lifetime prospects component, $\mathrm{Y}_{\mathrm{t}}^{\mathrm{L}}$. $\mathrm{Y}_{\mathrm{t}}^{\mathrm{L}}$, which is stochastic, depends on the individual family's current evaluation of its talents, special skills, and long-run opportunities. Since any change in this component is (virtually by definition) unanticipated, it is naturally modelled as a random walk:

$$
Y_{t}^{L}=Y_{t-1}^{L}+\varepsilon_{t}
$$

where the $\varepsilon_{t}$ are i.i.d., $N\left(0, \sigma_{\varepsilon}^{2}\right)$.

3. the windfall component, $Y_{t}^{W} \cdot Y_{t}^{W}$, also stochastic, is meant to capture purely transitory changes in income. For our data, inspection of the covariogram strongly suggests that $\mathrm{Y}_{t}^{\mathrm{W}}$ can be modelled as simple white noise:

$$
Y_{t}^{W}=n_{t}
$$

where the $\eta_{t}$ are i.i.d., $\mathrm{N}\left(0, \sigma_{\eta}^{2}\right) .^{8}$

A first step in our estimation below will be to eliminate $\bar{Y}_{t}$ from the income series. This will allow us to restrict our attention to the stochastic part of income, $Y_{t}$, defined by

$$
Y_{t} \equiv \tilde{Y}_{t}-\bar{Y}_{t}
$$


We will also make use of the first difference of stochastic income, $y_{t}$, given by

$$
y_{t} \equiv Y_{t}-Y_{t-1}=\varepsilon_{t}+\eta_{t}-\eta_{t-1}
$$

An issue of interest is the relation between revisions to permanent income and changes in the three components of current income. This relation is easy to find: All changes in the deterministic component $\bar{Y}_{t}$ are anticipated and do not affect $Y_{t}^{P}$. The current innovation to the lifetime prospects component, $\varepsilon_{t}$, represents a permanent increase in expected income and is thus fully reflected in the revision of $Y_{t}^{P}$. In contrast, the current innovation to the windfall component, $\eta_{t}$, is a one-shot addition to wealth; as such, it will increase $Y_{t}^{P}$ only at the rate that an addition to principal increases an annuity. In summary, we can write the current revision to permanent income as

$$
Y_{t}^{P}-Y_{t-1}^{P}=\varepsilon_{t}+\beta \eta_{t}
$$

where $\beta$ is the rate of payout of an annuity with a term equal to the lifespan of the family.

The standard assumption that consumption is proportional to permanent income, in conjunction with (2.5), gives the Hall (1978) "random walk consumption" result: Under the permanent income and rational expectations hypotheses, changes in consumption flows should be unpredictable. ${ }^{9}$ Note also that the covariance of (non-deterministic) 
consumption and current income changes is proportional to $\sigma_{\varepsilon}^{2}+\beta \sigma_{\eta}^{2}$. Thus, when most income changes are permanent $\left(\sigma_{\varepsilon}^{2} / \sigma_{\eta}^{2}\right.$ is large), consumption is very sensitive to current income. 10

The consumption-related variable in which we are specifically interested is family expenditure on automobiles, either purchases or sales, gross of depreciation. ${ }^{11}$ As with income, we assume that total expenditure $\tilde{E}_{t}$ is made of a deterministic (or non-family-specific) component and a stochastic component:

$$
\tilde{E}_{t}=\bar{E}_{t}+E_{t}
$$

Assuming that the deterministic component $\overline{\mathrm{E}}_{t}$ can be eliminated from the data, we concern ourselves here only with the stochastic portion of expenditure, $E_{t}$.

Under the familiar model of continuous stock adjustment, ${ }^{12}$ stochastic expenditure is given by

$$
(2.7) \quad E_{t}=\lambda\left(K_{t}^{*}-K_{t}\right)+\theta_{t}
$$

where $\lambda$ is the rate of stock adjustment; $\mathrm{K}_{\mathrm{t}}^{*}$ and $\mathrm{K}_{\mathrm{t}}$ are desired and actual car stocks (exclusive of the deterministic component) at the beginning of the period; and $\theta_{t}\left(i . i . d ., N\left(0, \sigma_{\theta}^{2}\right)\right)$ is a white noise term capturing random influences on expenditure.

By assuming smooth adjustment of the car stock we are ignoring (or at least relegating to the error term) the truncated dependent variable problem raised by Tobin (1958). While incorporating these 
considerations into our analysis poses no difficulty in principle, it would transform a computationally easy procedure into one that is extremely burdensome. Section 5 below discusses the implications of assuming continuous adjustment. The results of Monte Carlo simulations, to be reported, suggest that the biases introduced are small and easily corrected.

To make the desired car stock $K_{t}^{*}$ operational, we assume local linearity of the Engle curve for automobile services. ${ }^{13}$ This, plus the assumption that services are proportional to stocks, implies

$$
K_{t}^{*}-K_{t-1}^{*}=\alpha\left(Y_{t}^{P}-Y_{t-1}^{P}\right)
$$

where $\alpha$ measures the relation of desired stocks to permanent income. By $(2.5),(2.8)$ is equivalent to

$$
\mathrm{K}_{t}^{*}-\mathrm{K}_{\mathrm{t}-1}^{*}=\alpha\left(\varepsilon_{\mathrm{t}}+\beta \eta_{t}\right)
$$

To close the model, we write the evolution of the automobile stock $K_{t}$ as

$$
\mathrm{K}_{\mathrm{t}}=(1-\delta) \mathrm{K}_{\mathrm{t}-1}+\mathrm{E}_{\mathrm{t}-1}
$$

where $\delta$ is the rate of depreciation. ${ }^{14}$ Equation (2.7), (2.9), and (2.10) define a unique stochastic expenditure path, given a history of random disturbances $\varepsilon, \eta$, and $\theta$, and initial conditions for $k$ and $K^{*}$. 
Now let us drop the assumption of perfect capital markets. How should the expenditures of a family that is constrained in its borrowing and lending opportunities deviate from the above model? The argument presented by Mishkin (1976) is based on the observation that consumers with unfavorable balance sheets find it difficult to borrow. A series of short-run financial reverses may threaten insolvency and the loss of accumulated equity in debt-financed assets. Thus the family should try to maintain a buffer of financial assets over debt obligations. This leads to a dependence of car expenditure on the short-run level of financial liquidity, as well as on long-run income. ${ }^{15}$

A second possible effect of imperfect capital markets is drawn from the work of Darby (1972). If consumers do not have good short-run lending opportunities, they may choose to hold part of transitory income as durable goods. Thus automobile purchases may follow from portfolio considerations.

In the context of our model, both of these arguments suggest that car expenditures may be increased (dampened) in the short run by the effects of windfall gains (losses) on current financial holdings. We generalize (2.7) to

$$
E_{t}=\lambda\left(R_{t}^{*}-R_{t}\right)+\theta_{t}+m_{t}
$$

where $\gamma$ is a parameter that measures the response of expenditure to current windfall income.

Note that the specification (2.11) allows windfall income to affect short-run car stocks only; the long-run target $\mathrm{K}_{t}^{*}$, to which $\mathrm{K}_{t}$ 
converges, does not depend on the $\eta_{t}$ term. This is an important and desirable property of this specification. 16

We would like to test if $\gamma>0$. The procedure by which this is done is described in the next section. 


\section{Estimation Procedure}

The outline of the estimation approach can be briefly stated. We begin by finding the deviations of each family's car expenditure and changes in income from the corresponding deterministic paths. These deviations can be written as linear functions of unknown parameters and unobservable, family-specific shocks. Under the assumption of normality, it turns out that the average variance-covariance matrix of expenditure and differenced income is a sufficient statistic for the data. A maximum likelihood procedure can be used to extract estimates of the parameters, including the variances of the unobservable shocks.

For the interested reader, the rest of this section provides more detail. Others may wish to go directly to the results in Section 4. The basic data are the changes in real disposable income and the expenditures (purchases and sales) on automobiles of the families followed by the survey. (See the introduction and part 1 of the data appendix.) The estimation procedure required the data in the form of deviations from the deterministic paths. We assumed that the deterministic components were functions of family demographic characteristics and of year dummies. ${ }^{17}$ ordinary least-squares regressions in the pooled data were run for income change and car expenditure against the explanatory variables. (See data appendix, part 2.) The residuals of these regressions for each family and year were used to represent the nondeterministic components of income change and expenditure.

Inspection of these residuals revealed considerable heteroscedasticity across families of different income sizes. Since the estimation will assume that the sample families have identically distributed income 
innovations, a heteroscedasticity correction was necessary. The data appendix, part 3 , gives details. ${ }^{18}$

The next step is to write nondeterministic income change (y) and car expenditure (E) solely as functions of unobservables. ${ }^{19}$ For $\mathrm{y}$ this is easy; we already have (2.4). For $E$, this task is complicated by the fact that our expenditure data are gross rather than net of depreciation. It is shown in an appendix that current gross expenditure can be expressed, for any $k$, as

$$
\text { (3.1) } \quad E_{t}=\sum_{i=0}^{k} b_{i} L^{i} Z_{t}+b_{k+1} L^{k+1}\left(\lambda\left(K_{t}^{*}-K_{t}\right)+\theta_{t}\right)+a_{k+1} L^{k+1} K_{t}
$$

where

$$
\begin{aligned}
z_{t} & \equiv \lambda\left(k_{t}^{*}-k_{t-1}^{*}\right)+\theta_{t}-\theta_{t-1}+\gamma\left(n_{t}-\eta_{t-1}\right) \\
& =\lambda\left(\alpha\left(\varepsilon_{t}+\beta n_{t}\right)\right)+\theta_{t}-\theta_{t-1}+\gamma\left(n_{t}-\eta_{t-1}\right)
\end{aligned}
$$

The $\mathrm{L}^{i}$ are lag operators, and the $a_{i}$ and $b_{i}$ are parameters depending on $\lambda$ and $\delta$. Define an arbitrary beginning, or "base", year $t$ '. Let $K_{t^{\prime}}$, and $\left(K_{t^{\prime}}^{*}-K_{t^{\prime}}\right)$ be the base year (non-deterministic) car stock and the base year difference between desired and actual stocks, respectively. These can be thought of as unobserved random variables with unconditional means of zero and an unspecified covariance. Then, by (3.1), expenditure for any year depends on the history of disturbances and on the base year stock variables.

For a given family $i$, let $x_{i}$ be the column vector of unobserved random variables 
(3.3)

$$
\begin{aligned}
x_{i}^{\prime}= & \left(\varepsilon_{1964}, \ldots, \varepsilon_{1970}, \eta_{1963}, \ldots, n_{1970},\right. \\
& \left.\theta_{1963}, \ldots, \theta_{1970}, K_{1963},\left(K^{*}-K\right)_{1963}\right)
\end{aligned}
$$

We assume that $x_{i}$ is multivariate normal with covariance matrix $\Sigma$. $\Sigma$ is supposed to be diagonal, except for the covariance of the last two terms. The variances on the diagonal are

$$
\begin{aligned}
v\left(\varepsilon_{t}\right) & =\sigma_{\varepsilon}^{2} \\
v\left(\eta_{t}\right) & =\sigma_{\eta}^{2} \\
V\left(\theta_{t}\right) & =\sigma_{\theta}^{2} \\
v\left(k_{1963}\right) & =\sigma_{k}^{2} \\
V\left(\left(K^{*}-k\right)_{1963}\right) & =\sigma_{k^{*}}^{2}
\end{aligned}
$$

Define $q_{i}$ to be the colum vector in which is stacked the 1 -th family's history of income change and expenditure. Then, using (2.4) and (3.1), the model to be estimated can be expressed in the form:

$$
q_{i}=\operatorname{Ax}_{i}
$$

Where $A$ is a $6 \times 25$ matrix which depends on unknown parameters. The covariance matrix for the representative family is

$$
\Omega(P)=A \Sigma A^{\prime}
$$


$P$ is a vector of unknown paramters:

$$
\text { (3.7) } \quad P^{\prime}=\left(\alpha, \beta, \delta, \gamma, \lambda, \sigma_{\varepsilon}^{2}, \sigma_{\eta}^{2}, \sigma_{\theta}^{2}, \sigma_{k}^{2}, \sigma_{k^{*}}^{2}, \rho_{k k^{*}}\right)
$$

The log-likelihood of a sample of size $\mathrm{N}$ is

$$
\text { (3.8) } \quad L(P)=-\frac{N}{2} \log \operatorname{det} \Omega(P)-\frac{1}{2} \sum_{i=1}^{N} q_{i} \Omega^{-1}(P) q_{i}
$$

plus an inessential constant. Maximization of (3.8) with respect to the unknown parameters produces estimates with the usual desirable properties. A numerical maximization routine written by Bronwyn Hall (1979) was available for the estimation.

We did not attempt to estimate the full parameter vector $P$. The annuity rate $\beta$ was exogenously specified to be equal to $.03 .{ }^{20}$ Following estimates by Cagan (1971), we set the annual rate of stock depreciation $\delta$ equal to a constant $.25 .^{21}$

We found by experiment that, although we could estimate the variance of $\mathrm{K}_{1963}$, the variance of $\left(\mathrm{K}_{1963}^{*}-\mathrm{K}_{1963}\right)$ and its covariance with $\mathrm{K}_{1963}$ could not be econometrically identified. Using Monte Carlo simulations as a guide, we tried different exogenous values for these terms. The results were found to be essentially invariant to the treatment of $\left(\mathrm{K}_{1963}^{*}-\mathrm{K}_{1963}\right)$; moving the variance and covariance terms over a reasonable range affected the estimates, except for that of $\sigma_{k}^{2}$, by one percent or less. In the estimates reported in the next section we simply assumed 
(3.9)

$$
K_{1963}^{*}=K_{1963}
$$

That is, families are assumed to have had no gap between desired and actual car stocks in the base year. 


\section{Estimation Results}

The parameter estimates that maximized (3.8) for the sample are given in Table 1. The four variance parameters (1-4) are measured in millions of 1972 dollars; they have been scaled up to offset the cross-sectional heteroscedasticity correction.

The model fits the data well. The variance parameters are of reasonable magnitude ${ }^{22}$ and are sharply estimated. We find the variances of innovations to lifetime prospects and windfall components of income to be similar in size. ${ }^{23}$ The estimated variance of $\theta$, the expenditure disturbance, is about $80 \%$ of the total variance of automobile expenditure; presumably this includes the effects of non-continuous stock adjustment and errors of measurement in $E_{t}$.

The annual rate of stock adjustment, $\lambda$, is found to be .694 . Since a given family's car expenditures are non-zero only about one year in three, this may appear high. However, it is probably the case that expenditures are more likely to be made in years in which significant changes to desired stocks have occurred. Thus $\lambda$ must exceed one-third.

The estimate of $\alpha$ says that a one dollar increase in permanent income will lead, in the long run, to a 25.9 cent increase in the value of the family's car stock. We made several checks of this estimate:

1) Using reported characteristics of car stocks, we were able to construct estimates of each family's car stock value for each year. These values were not used in obtaining the above estimate 
Table 1

PARAMETER ESTIMATES

ENTIRE SAMPLE

\begin{tabular}{|c|c|c|}
\hline Parameter & $\begin{array}{c}\text { Estimate } \\
(t-s t a t i s t i c)\end{array}$ & Parameter Definition \\
\hline 1. $\sigma_{n}^{2}$ & $\begin{array}{c}5.64 \\
(18.26)\end{array}$ & $\begin{array}{l}\text { Variance of windfall shocks } \\
\text { to income }\end{array}$ \\
\hline 2. $\sigma_{\varepsilon}^{2}$ & $\begin{array}{c}4.79 \\
(11.08)\end{array}$ & $\begin{array}{l}\text { Variance of lifetime shocks } \\
\text { to income }\end{array}$ \\
\hline 3. $\sigma_{\theta}^{2}$ & $\begin{array}{c}1.96 \\
(19.71)\end{array}$ & $\begin{array}{l}\text { Variance of random influences } \\
\text { on expenditure }\end{array}$ \\
\hline 4. $\sigma_{k}^{2}$ & $\begin{array}{c}25.11 \\
(15.22)\end{array}$ & Variance of initial stocks \\
\hline 5. $\lambda$ & $\begin{array}{r}.694 \\
(18.55)\end{array}$ & $\begin{array}{l}\text { Annual rate of stock } \\
\text { adjustment }\end{array}$ \\
\hline 6. $\alpha$ & $\begin{array}{r}.259 \\
(6.09)\end{array}$ & $\begin{array}{l}\text { Response of desired stock to } \\
\text { changes in long-run income }\end{array}$ \\
\hline 7. $r$ & $(-0.71)$ & $\begin{array}{l}\text { Sensitivity of current expen- } \\
\text { diture to current transitory } \\
\text { income }\end{array}$ \\
\hline
\end{tabular}


of $\alpha$, except in the constructing of series for the value of car sales unaccompanied by purchases. Using two-stage least-squares to eliminate transitory income effects, we regressed each family's average real stock value over the period against average disposable income, age of the head, age squared, and a constant. The estimated coefficient, of income (a measure of $\alpha$ ) was .219. See the data appendix, part 4 .

2) The Survey of Current Business has recently reported aggregate constant-dollar automobile stocks for 1964-79. A simple regression of stocks against real personal disposable income and a constant gave an estimate of $\alpha$ of .227.

These confirmations that $\hat{\alpha}$ is in a reasonable range increase our confidence in the model. 24

The estimate of greater interest is that of $\gamma$, the parameter that measures the "excess" sensitivity of expenditure to windfall income. Recall that, for a family that faces constraints in the capital market, we expect $\gamma>0$. The actual estimate of $\gamma$ is negative, small, and insignificantly different from zero. Thus we have found no evidence of excessive sensitivity of car expenditure to transitory income change, and, a fortiori, no evidence of imperfections in the capital markets faced by consumers. 25 This conclusion runs counter to the results of the previously mentioned work by Mishkin $(1976,1977)$, in which time series data was used to find a link between durables expenditure and consumer holdings of liquid assets and debt. ${ }^{26}$ We performed an additional test for 
Table 2

PARAMETER ESTIMATES

HIGH FINANCIAL ASSETS SUBSAMPLE

Estimate
Parameter $\quad$ Parameter Definition

1. $\sigma_{\eta}^{2}$

2. $\sigma_{\varepsilon}^{2}$

3. $\sigma_{\theta}^{2}$

4. $\sigma_{\mathrm{k}}^{2}$

5. $\lambda$

6. $\alpha$

7. $\gamma$

$$
6.61
$$$$
\text { (8.06) }
$$

\subsection{9}

(13.03)

39.12

(8.57)

.624

$(10.96)$

.237

(4.42)

.023

$(0.498)$
Variance of windfall shocks to income

Variance of lifetime shocks to income

Variance of random influences on expenditure

Variance of initial stocks

Annual rate of stock adjustment

Response of desired stock to changes in long-run income

Sensitivity of current expenditure to current transitory income 
liquidity effects, as follows: Family financial assets, including bank deposits and holding of stocks and bonds (but not currency) are available for each year. Real financial assets were regressed against demographic variables to permit the creation of a "fitted" level of financial assets for each family. The sample was ranked by the average level of fitted financial assets over the period. The basic model was then re-estimated for the top third and the bottom third of the sample. The presumption was that, if the liquidity hypothesis is correct, a greater sensitivity to windfall income would be found among those with small financial holdings. 27 The outcome of this exercise is contained in Tables 2 and 3.

Surveying the results, we see that the "rich" are more likely to experience lifetime rather than windfall income changes, while for the "poor" the reverse is true. ${ }^{28}$ The high-financial-asset group had larger initial car stocks and more car expenditures, but a lower marginal propensity to buy cars than the low-asset group. The rate of stock adjustment was comparable in the two subsamples, with, surprisingly, slightly faster adjustment by the low-asset people.

Most importantly, estimates from neither subsample can support the hypothesis that $\gamma>0$. of the two point estimates, the negative (and marginally significant) one was associated with the low-asset group, the positive one with the high-asset subsample. This is the opposite ordering that would be predicted by the liquidity hypothesis. Based on this evidence, there is no reason to believe that 1iquidity considerations affect even the timing of automobile expenditures. 
Table 3

PARAMETER ESTIMATES

LOW FINANCIAL ASSETS SUBSAMPLE

\begin{tabular}{|c|c|c|}
\hline Parameter & $\begin{array}{c}\text { Estimate } \\
(t-\text { statistic })\end{array}$ & Parameter Definition \\
\hline 1. $\sigma_{\eta}^{2}$ & $\begin{array}{c}3.50 \\
(12.49)\end{array}$ & $\begin{array}{l}\text { Variance of windfall } \\
\text { shocks to income }\end{array}$ \\
\hline 2. $\sigma_{\varepsilon}^{2}$ & $\begin{array}{l}1.66 \\
(4.76)\end{array}$ & $\begin{array}{l}\text { Variance of lifetime } \\
\text { shocks to income }\end{array}$ \\
\hline 3. $\sigma_{\theta}^{2}$ & $\begin{array}{r}.959 \\
(10.11)\end{array}$ & $\begin{array}{l}\text { Variance of random } \\
\text { influences on expenditure }\end{array}$ \\
\hline 4. $\sigma_{\mathrm{k}}^{2}$ & $\begin{array}{l}10.37 \\
(5.65)\end{array}$ & Variance of initial stocks \\
\hline 5. $\lambda$ & $\begin{array}{r}.687 \\
(10.49)\end{array}$ & $\begin{array}{l}\text { Annual rate of stock } \\
\text { adjustment }\end{array}$ \\
\hline 6. $\alpha$ & $\begin{array}{l}.461 \\
(4.00)\end{array}$ & $\begin{array}{l}\text { Response of desired stock } \\
\text { to changes in long-run } \\
\text { income }\end{array}$ \\
\hline 7. $\gamma$ & $\begin{array}{r}-.053 \\
(-1.96)\end{array}$ & $\begin{array}{l}\text { Sensitivity of current } \\
\text { expenditure to current } \\
\text { transitory income }\end{array}$ \\
\hline
\end{tabular}




\section{The Discontinuous Adjustment Problem}

The well-known desirable properties of maximum likelihood estimation are, of course, contingent on proper specification of the model. However, both experience and theoretical considerations ${ }^{29}$ suggest that ML can be an effective approach when the statistical model is only approximately correct. We tested the robustness of our estimates to various specification errors by Monte Carlo simulations, with generally good results.

A possible specification error of particular interest was the assumption of continuous stock adjustment. Since Tobin (1958) it has been standard in cross-sectional studies to model purchases of durable goods as taking place only when the gap between desired and actual stocks exceeds some threshold level. ${ }^{30}$ This discontinuous adjustment is consistent with the fact that family purchases of a given durable are zero in most years. While computational considerations forced us to ignore discontinous adjustment, it is important to know what potential biases exist. 31

In terms of the notation of this paper, the discontinous adjustment mode1 is

$$
\begin{aligned}
& E_{t}^{*}=\lambda\left(R_{t}^{*}-R_{t}\right)+\theta_{t}+\eta_{t} \\
& E_{t}=\left\{\begin{array}{l}
E_{t}^{*} \text { if } E_{t}^{*}>\bar{I} \text { or } E_{t}^{*}<\underline{I} \\
0 \text { otherwise }
\end{array}\right.
\end{aligned}
$$

where $\bar{I}$ and $\underline{L}$ are the thresholds beyond which the family will buy or sell automobiles. The specification is closed by adding equations (2.4), (2.9), and (2.10). 
This model, in conjunction with a normal random number generator, was used to create artificial data sets. The variances of the disturbances and the thresholds were chosen so that the purchase frequency and other characteristics of the actual data were approximated. The other parameters were varied over plausible ranges. Each run simulated the behavior of 200, 300, or 400 "families" over fifteen "years". Only the last four years were assumed to be "observed"; the purpose of the first eleven "years" was to generate appropriate random initial conditions. The average income-expenditure covariance matrix for the final four years was input to the basic estimation procedure (which assumes continuous adjustment), and the results were compared to the "true" parameters of the simulation.

While the cost of a completely formal robustness analysis did not seem justified, sixteen simulations and estimations were performed. These seemed sufficient for making the following observations:

1) The sample sizes used (one-third or less of the actual sample size) were adequate to allow low-variance estimates of all parameters.

2) Estimates of the income disturbance variances were easy to obtain.

3) We observed a small positive bias in the estimate of $\alpha$, in the vicinity of .03 . Twelve of the sixteen simulations led to an estimate of $\alpha$ that was too high. The empirical standard deviation of the estimation of $\alpha$ was about .05 for samples of 400 .

4) Estimates of $\gamma$ showed a bias of approximately -.025 . Except for this bias, $\gamma$ was tightly and reliably estimated: In every simulation and estimation run, even those in which other estimates 
were unusually inaccurate, $\hat{\gamma}$ fell in the range $(\gamma-.01, \gamma-.04)$.

We conclude that violation of the assumption of continuous stock adjustment does not pose a severe problem for our results. Correction of the full-sample estimate of $\gamma$ for the empirical bias gives a value that is positive but still very close to zero. The marginally significant negative $\hat{\gamma}$ found in the low-asset sub-sample is shown by the simulation studies to be an artifact. However, no additional explanation can be offered for the positive $\gamma$ in the high-asset group. 


\section{Conclusion}

This study tested the joint rational expectations - permanent income hypothesis using panel data on automobile expenditures. Although it would seem that durables purchases would be especially sensitive to failures of the PIH, no evidence against the joint hypothesis was found. How can the conclusion that automobile expenditures depend on the consumer's long-run view of his income be squared with the short-run volatility of car sales in the aggregate? While this must be left to future research, it is not anticipated that the reconciliation will be difficult. First, the estimates presented imply that a one-dollar increase in current disposable income that is expected to be permanent will lead to a seventeen-cent expansion in car sales the first year. (In comparison, average car sales are about five percent of disposable income.) This, in conjunction with the fact that aggregate income contains a significant random walk component, leaves room for powerful accelerator effects. Second, by construction our study eliminated some non-income factors that may be important for car sales in the aggregate: Relative prices, interest rates," and "confidence" 33 all may contribute to observed short-run variations. Thus, we may hope to explain cycles in aggregate automobile purchases without reliance on an "excessive" sensitivity of expenditure to current income. 
Appendix. Derivation of the expression for gross automobile expenditures

The model for gross expenditures (using the notation of the text) is

$$
E_{t}=\lambda\left(K_{t}^{*}-K_{t}\right)+\theta_{t}+\gamma m_{t}
$$

Where $E_{t}$, $K_{t}^{*}$, and $K_{t}$ are defined to be net of their deterministic components. K evolves as

$$
K_{t}=(1-\delta) K_{t-1}+E_{t-1}
$$

Differencing (1) gives:

$$
E_{t}=\lambda\left(K_{t}^{*}-K_{t-1}^{*}\right)-\lambda\left(K_{t}-K_{t-1}\right)+\theta_{t}-\theta_{t-1}+\gamma\left(\eta_{t}-\eta_{t-1}\right)+E_{t-1}
$$

Differencing (2) and substituting:

$$
E_{t}=\lambda\left(K_{t}^{*}-K_{t-1}^{*}\right)-\lambda\left(E_{t-1}-\delta K_{t-1}\right)+\theta_{t}-\theta_{t-1}+\gamma\left(\eta_{t}-\eta_{t-1}\right)+E_{t-1}
$$

or

$$
E_{t}=z_{t}+(1-\lambda) E_{t-1}+\lambda \delta K_{t-1}
$$

where

$$
z_{t} \equiv \lambda\left(K_{t}^{*}-K_{t-1}^{*}\right)+\theta_{t}-\theta_{t-1}+\gamma\left(n_{t}-n_{t-1}\right)
$$


Using (5) it can be shown that, for any $k \geq 1$

$$
E_{t}=c_{k-1}+b_{k} L^{k} E+a_{k} L^{k} K
$$

where

$$
\begin{aligned}
c_{j} & \equiv \sum_{i=0}^{j} b_{i} L^{i} z_{t} \\
a_{0} & =0 \\
b_{0} & =1 \\
a_{j+1} & =a_{j}(1-\delta)+\lambda \delta b_{j} \\
b_{j+1} & =a_{j}+(1-\lambda) b_{j}
\end{aligned}
$$

and $L$ is the lag operator.

Proof of (6) is by induction. For $k=1,(6)$ reduces to (5). Now suppose that (6) is true for $k$. Substitute (5) and (2) into (6) to get

$$
E_{t}=c_{k-1}+b_{k} L^{k}\left(z_{t}+(1-\lambda) L E_{t}+\lambda \delta L K_{t}\right)+a_{k} L^{k}\left((1-\delta) L K_{t}+L E_{t}\right)
$$

This implies

$$
E_{t}=\left(c_{k-1}+b_{k} L^{k} z_{t}\right)+\left(a_{k}+b_{k}(1-\lambda)\right) L^{k+1} E_{t}+\left(a_{k}(1-\delta)+\lambda \delta b_{k}\right) L^{k+1} K_{t}
$$

which is just

$$
E_{t}=c_{k}+b_{k+1} L^{k+1} E_{t}+a_{k+1} L^{k+1} k_{t}
$$


Q.E.D.

(9) is equivalent to

$$
E_{t}=\sum_{i=0}^{k} b_{i} L^{i} z_{t}+b_{k+1} L^{k+1}\left(\lambda\left(K_{t}^{*}-K_{t}\right)+\theta_{t}\right)+a_{k+1} L^{k+1} K_{t}
$$

which is used in the text. 


\section{Data Appendix}

This appendix describes data sources and construction, and provides details on some preliminary steps in the estimation procedure.

The primary source of data was the Hendricks-Youmans (1976) four-year panel study of consumer behavior. Their study was conducted at the University of Michigan's Survey Research Center as an adjunct to the annual Survey of Consumer Finances. 1434 families, representing a national cross-section, were interviewed each year from 1967 to 1970 .

1. Data construction. The basic variables in our study were real family disposable income and gross expenditures on automobiles. These were constructed as follows:

Total income is reported each year in current dollars. It includes capital and mixed labor-capital income, as well as wages and salaries. Unrealized capital gains do not appear to be included. Federal taxes were estimated from the family data by the survey-taking group. We estimated Social Security and state income taxes for each family:

1) Total family income was allocated into wages, non-wage taxable, and non-taxable income. The appropriate Social Security tax rate, subject to the legislated ceiling, was applied to each of the first two categories to estimate Social Security taxes.

2) For each state and each year, we found the ratio of state personal income taxes to Federal personal income taxes paid by inhabitants of the state. ${ }^{34}$ The applicable ratio was applied to each family's estimated Federal taxes to calculate the family's state taxes for that year. 
Sales taxes and property taxes were not deducted, on the grounds that they should be treated as part of the price of the associated consumer good.

Income measures were converted to 1972 dollars by the implicit deflator for the personal consumption expenditures component of GNP. The survey contained annual data on gross expenditures on automobiles for each family. However, car sales that were not trade-ins were not reported. We augmented the expenditure data with a car sales series constructed from data on family car stocks.

Each family reported the number of cars owned in each year and a list of characteristics of the primary car. We estimated the value of the primary car in a manner to be described. When the number of cars owned was unaccountably too low, based on previous stocks and expenditures, it was assumed that a sale had taken place. If it could be determined that the primary car had been sold without an accompanying purchase, the value of the primary car was included in the sales series. If it was not the primary car that was sold, we assumed that the "last" of the $n$ cars owned by the family was sold. This car was valued at $1 / n$ times the value of the primary car.

Valuation of the primary car was achieved by fitting a regression of the purchase prices of cars bought during the sample period against the characteristics of those cars. Using the characteristics of the primary cars, the regression predicted primary car values. The predicting regression was 

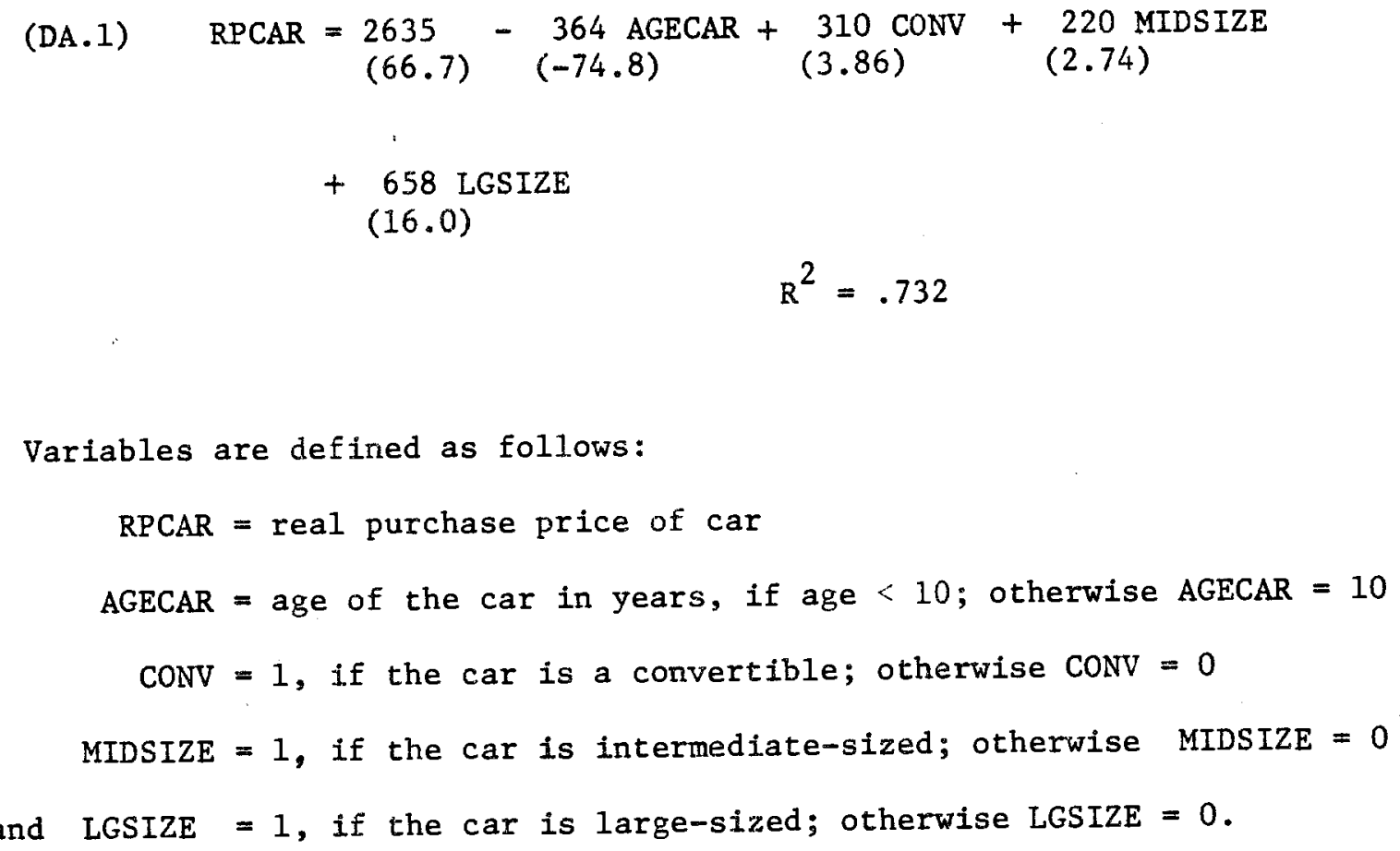

The t-statistics are in parentheses.

Automobile expenditures were deflated by the automobiles component of the Consumer Price Index.

2. Elimination of deterministic components. A first step in the estimation procedure is to remove the "deterministic" components of family income and automobile expenditure. As in Bhalla (1980), our approach was to extrapolate time series profiles from the essentially cross-sectional data. The prediction regressions for the first difference of real disposable income and for real automobile expenditures were: 


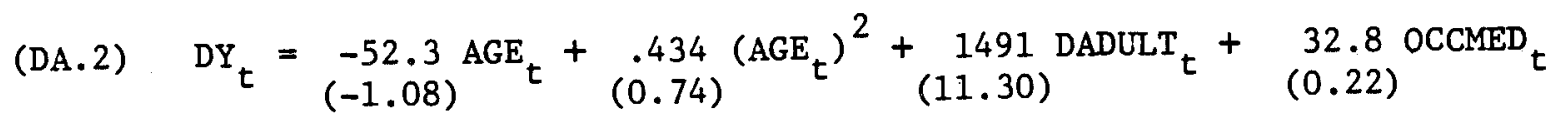

$$
\begin{aligned}
& +\underset{(0.58)}{89.4 \text { OCCHI }_{t}}+\underset{(1.90)}{1843 \mathrm{YR} 1}+\underset{(1.65)}{1598 \mathrm{YR} 2}+\underset{(1.71)}{1658 \mathrm{YR} 3} \\
& \mathrm{R}^{2}=.045
\end{aligned}
$$

and

$$
\begin{aligned}
& \text { (DA.3) } \operatorname{EXP}_{t}=\underset{(0.76)}{13.0 \mathrm{AGE}_{t}}-\underset{(-0.86)}{.176}\left(\mathrm{AGE}_{t}\right)^{2}+\underset{(2.65)}{96.3} \mathrm{ADULT}^{2}+\underset{(4.02)}{215 \text { OCCMED }_{t}} \\
& +\underset{(5.53)}{298 \mathrm{OCCHI}_{\mathrm{t}}}-\underset{(0.06)}{18.9 \mathrm{YR} 1}+\underset{(0.10)}{34.5 \mathrm{YR} 2}-\underset{(-0.05)}{15.8 \mathrm{YR} 3} \\
& \mathrm{R}^{2}=.156
\end{aligned}
$$

The variable definitions are

$$
\begin{aligned}
& D Y_{t}=\text { change in real disposable income between years } t \text { and } t+1 \\
& \operatorname{EXP}_{t}=\text { real automobile expenditures in year } t \\
& \mathrm{AGE}_{t}=\text { age of head of household at end of year } t \\
& \text { ADULT }_{t}=\text { number of adults in household at end of year } t \\
& \text { DADULT }_{t}=\text { ADULT }_{t+1}-\text { ADULT }_{t} \\
& \mathrm{OCCMED}_{t}=1 \text { if } 30 \leq \mathrm{OCC}_{t} \leq 59, \quad 0 \text { otherwise } \\
& \text { OCCHI }_{t}=1 \text { if } 60 \leq 0 \mathrm{OC}_{t}, \quad 0 \text { otherwise } \\
& \text { where } \mathrm{OCC}_{t}=\text { Duncan socioeconomic status score of occupation of } \\
& \text { family head. The scale is } 0-100 \text {, with higher scores } \\
& \text { corresponding to higher status. Because the score is } \\
& \text { not reported for } 1970 \text {, we assumed } \mathrm{OCC}_{1970}=\mathrm{OCC}_{1969} \text { for } \\
& \text { each family }
\end{aligned}
$$


YR1, YR2, YR3 = year dummies, 1968-70.

Pooled data were used. The "deterministic" components of income change and expenditure were taken to be the predictions of these regressions for each family.

3. Heteroscedasticity adjustment. The data were adjusted for heteroscedasticity in the innovations to income. A simple Wald approach was used: First, the four-year average disposable income for each family was calculated. The range of average incomes was then broken up into $\$ 5000$ intervals. (The large interval size was chosen in order to keep induced bias at a minimum.) The normalizing factor assigned to each family was the mean of all incomes falling in the same interval as the income of the family. Income and expenditure were divided by the normalizing factor before estimation.

4. Alternative estimate of $\alpha$. To find an alternative estimate of the sensitivity of long-run car stocks to permanent income, we ran the following regression:

$$
\begin{gathered}
(\mathrm{DA} .4) \text { CARSTOCK }=\frac{2625}{(8.02)}+\underset{(26.0)}{.219 \mathrm{YPERM}-\underset{(-8.84)}{\left(152 \mathrm{AGE}_{1968}\right.}+1.67\left(\mathrm{AGE}_{1968}\right)^{2}} \\
\mathrm{R}^{2}=0.116
\end{gathered}
$$

where

$$
\begin{aligned}
\text { CARSTOCK = } & \text { estimated value of family's car stock, averaged over } \\
& \text { sample period }
\end{aligned}
$$




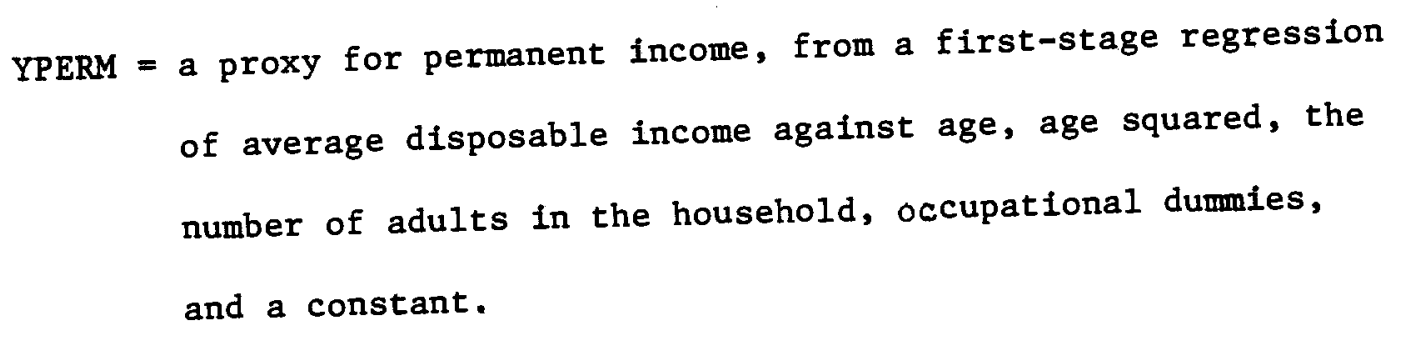

5. Partitioning the sample by liquidity levels. The sample was subdivided in order to do the estimation reported in section 4. First, the holdings of real, liquid financial assets for each year in the sample period were calculated for each family. Pooling years 1968-70, liquid assets was fitted against demographic data as follows:

$$
\begin{aligned}
& \text { (DA.5) } \quad \text { FIN }_{t}=\underset{(-0.79)}{-2116}+\underset{(0.01)}{1.64} \mathrm{AGE}_{t}+\underset{(1.68)}{2.60}(\mathrm{AGE})^{2}-\underset{(0.85)}{230 \mathrm{ADULT}_{\mathrm{t}}} \\
& +\underset{(9.22)}{3760 \text { OCCMED }_{t}}+\begin{array}{l}
7200 \text { OCCHI } \\
(17.7)
\end{array} \\
& \mathrm{R}^{2}=.121
\end{aligned}
$$

Predicted liquid assets for each family were averaged over the sample period. Families were then ranked according to average predicted liquid assets, and the sample broken into thirds. 
Notes

1. For example, it is central to the debate over the effectiveness of temporary income tax changes as countercylical instruments. See B1inder (1981).

2. See, e.g.,Modigliani-Brumberg (1954) and Ando-Modigliani (1963).

3. The older reserach is surveyed in Ferber (1973) and Mayer (1972).

4. Hal1-Mishkin used Michigan's Pane1 Study of Income Dynamics, which contains histories of 2309 families over the period 1969-75.

5. For this reason Hall-Mishkin single out the extension of their approach to durables as an important topic for further research.

6. The Hall, Sargent, and Flavin time serfes studies treated all income changes as homogeneous; the asstmption that families can distinguish different types of income change seems more reasonable. Earlier work tried to operationalize this assumption by breaking income down by source (see, for example, Taylor (1971)); but the identification of, say, capital income with windfalls is arbitrary. The use of an unobservables model here avoids these problems.

7. Alternatively, $\bar{Y}_{t}$ could be called the non-family-specific component. $\bar{Y}_{t}$ is supposed to capture "standard" income profiles for each demographic group, from which changes in the fortunes of individual families can be measured as deviations.

8. We did experiment with alternative ARMA processes for windfall income; processes with two or less free parameters could be identified in the context of our model. Our findings were not sensitive to these changes.

9. This assumes that income is exogenous with respect to consumption. Sargent's article has a discussion of the implications of this. The income-exogeneity assumption is more easily avoided in time series than in panel data; see Diewert (1974) for an application to durables.

10. The point that the sensitivity of consumption to current income under the PIH depends on the stochastic process of income is amplified by Flavin and by Blinder. 
11. Because of the durable-goods feature of this problem, we depart from the Hal1-Mishkin specification at this point.

12. Stone and Rowe (1957).

13. At best this is an approximation. Estimation within high- and low-income subsamples showed that in fact the marginal propensity to buy cars is lower for the rich. However, this fact did not affect the estimates of the other parameters, which were about the same in the subsamples as in the total sample.

14. Geometric mortality is a standard assumption. For alternative models of durables stock depletion, see Williams (1972).

15. For an early statement of this idea, see Nugent (1939), especially p. 135. Mishkin's analysis can be viewed as the opposite face of the precautionary demand for money literature (see, e.g., Whalen (1966)). We find this treatment of dynamic liquidity management under uncertainty to be much richer than the older, static model of liquidity constraints, in which spending is affected only when cash reserves literally reach zero.

16. Specifically, (2.11) implies that expenditures deferred (or moved up) this year are made up at rate $\lambda$ in future years, leaving no long-run effects. Alternative specifications tried assumed 1) that deferred expenditures are made up completely in the next year, and/or 2) current deferrals depend on a moving average of past and present windfalls, rather than just the current windfall. The results were not significantly affected by these changes.

17. Year dummies were included to eliminate aggregate influences such as the business cycle, interest rates, and the relative price of automobiles; we wanted to avoid the possibility of one or two macroeconomic events dominating the results. Using the year dummies in fact made little difference, confirming the observation that aggregate disturbances explain only a small part of the variation in individual family circumstances.

18. In the original application of this approach, Hall and Mishkin did not make a cross-sectional heteroscedasticity correction. This is a potentially serious omission, since it gives some large-income families as much as one hundred times the average weight in the estimates. We also suspect that it is this omission that pushes the Hall-Mishkin results away from acceptance of the PIH.

19. The use of income changes and car expenditure levels is not asymetrical: Expenditures are the first difference of stocks, which depend on (permanent) income. 
20. The parameter estimates were not at all sensitive to changes in $\beta$. Specifically, the convenient assumption that $\beta$ is constant across the sample, rather than dependent on the age of the family head, was not a factor in the results.

21. Wykoff (1970) disputes the constant depreciation rate assumption, claiming that depreciation is at a greater rate in the first year. The effects of experimentation with the depreciation rate were confined largely to the estimates of the stock adjustment parameter, $\lambda$.

22. $\hat{\sigma}_{\mathrm{k}}^{2}$ is inflated in some degree by the assumption that the unidentifiable term $\sigma_{\mathrm{k}^{*}}^{2}$ equals zero.

23. The Hall-Mishkin result that $\sigma_{\eta}^{2}$ is about twice $\sigma_{\varepsilon}^{2}$ may be due to the cross-sectional heteroscedasticity in their data. Our uncorrected data also implied a relatively larger variance for windfall income.

24. In addition, Monte Carlo simulations, reported below, found an estimated bias in $\hat{\alpha}$ of approximately .03. Correction of $\hat{\alpha}$ by this quantity brings it very close to the alternative estimates.

25. Few previous studies of automobile expenditure have explicitly considered the influence of transitory income. An exception is Katona and Mueller (1968) who, applying a rather different approach to family data, tend to support the no-effect result.

26. In his comment following Mishkin (1977), Robert Gordon pointed out some difficulties in interpreting the time series tests of the liquidity hypothesis. The use of cross-sectional data helps us avold those problems in the test reported below.

27. The division of the sample by fitted rather than actual financial assets was done to avoid simultaneity problems, e.g., as when a family cumulates financial assets in anticipation of a car purchase. The estimates of $\gamma$ were about the same when the sample was divided according to actual financial assets.

28. We had no prior reason to expect this result, but it was obvious even from casual inspection of the autocovariograms of income. Again, variances are scaled to offset the heteroscedasticity correction.

29. For example, see MaCurdy (1981) on ML properties when disturbances are incorrectly assumed to be normal.

30. Dagenais (1975) and others have expanded on the basic Tobit model. 
31. Determination of the bias analytically seems intractable. The problem is complicated by the time series aspect and by the inclusion of car sales as well as purchases.

32. Hamburger (1967).

33. Hymans (1970) and Juster-Wachtel (1972) have stressed the importance of survey measures of consumer sentiment in predicting short-run car sales. For formal analyses of the "confidence" phenomenon as a result of the interaction of uncertainty and irreversibility, see Cukierman (1980) and Bernanke (forthcoming).

34. Sources were 1) for federal personal income taxes by state: Internal Revenue Service, Statistics of Income: Individual Income Tax Returns; 2) for state personal income taxes, Commerce Clearing House, State Tax Handbook, various years. 


\section{References}

Ando, Albert and Franco Modigliani, "The Life-Cycle Hypothesis of Saving," American Economic Review, 53, March 1963, 55-84.

Bernanke, Ben, "Irreversibility, Uncertainty, and Cyclical Investment," Quarterly Journal of Economics, forthcoming.

Bhalla, Surjit, "The Measurement of Permanent Income and Its Application to Savings Behavior," Journal of Political Economy, 88, August 1980, 722-44.

Blinder, Alan, "Temporary Income Taxes and Consumer Spending," Journal of Political Economy, 89, February 1981, 26-53.

Cagan, Phillip, "Measuring Quality Changes and the Purchasing Power of Money: An Exploratory Study of Automobiles," in Z. Griliches, ed., Price Indexes and Quality Change, Cambridge: Harvard Univ. Press, 1971 .

Cukierman, Alex, "The Effects of Uncertainty on Investment Under Risk Neutrality with Endogenous Information," Journal of Political Economy, 88, June 1980, 462-75.

Dagenais, Marcel, "Application of a Threshold Model to Household Purchases of Automobiles," Review of Economics and Statistics, 57, August $1975,275-85$.

Darby, Michael, "The Allocation of Transitory Income Among Consumer Assets," American Economic Review, 62, December 1972, 928-41.

Diewert, W. E., "Intertemporal Consumer Theory and the Demand for Durables," Econometrica, 42, May 1974, 497-516.

Ferber, Robert, "Consumer Economics: A Survey," Journal of Economic Literature, 11, 1973, 1303-42.

Flavin, Marjorie, "The Adjustment of Consumption to Changing Expectations about Future Income," Journal of Political Economy, forthcoming.

Friedman, Milton, A Theory of the Consumption Function, Princeton, N.J.: Princeton Univ. Press, 1957.

Ha11, Bronwyn, MOMENTS: The Moment Matrix Processor User's Manual, Version $1 . \overline{1,1979 .}$

Ha11, Robert, "Stochastic Implications of the Life Cycle-Permanent Income Hypothesis: Theory and Evidence," Journal of Political Economy, 86, December 1978, 971-87.

and Frederic Mishkin, "The Sensitivity of Consumption to Transitory Income: Estimates from Panel Data on Households," Econometrica, forthcoming. 
Hamburger, Michael, "Interest Rates and the Demand for Consumer Durable Goods," American Economic Review, 57, December 1967, $1131-53$.

Hendricks, Gary and Kenwood Youmans, Consumer Durables and Installment Debt: A Study of American Households, 1967-70, Inter-university Consort fum for Political and Social Research, Ann Arbor, 1976, Report \# ICPSR7497.

Hymans, Saul, "Consumer Durable Spending: Explanation and Prediction," Brookings Papers on Economic Activity, 1970:2, 173-206.

Juster, F. Thomas and Paul Wachtel, "Anticipatory and Objective Models of Durable Goods Demand," American Economic Review, 62, September $1972,564-79$.

Katona, George and Eva Mueller, Consumer Response to Income Increases, Washington: Brookings Institution, 1968 .

Lucas, Robert, "Econometric Policy Evaluation: A Critique," in K. Brunner and A. Meltzer, Eds., The Phillips Curve and Labor Markets, Amsterdam: North-Holland, 1976 .

MaCurdy, Thomas, "Asymptotic Properties of Quasi-Maximum Likelihood Estimators and Test Statistics," National Bureau of Economic Research, Technical Paper \#14, June 1981.

Mayer, Thomas, Permanent Income, Wealth, and Consumption, Berkeley: Univ. of California Press, 1972 .

Mishkin, Frederic, "Illiquidity, Consumer Durable Expenditure, and Monetary Policy," American Economic Review, 66, September 1976, 642-54.

, "What Depressed the Consumer? The Household Balance Sheet and the 1973-75 Recession," Brookings Papers on Economic Activity, $1977: 1,123-64$.

Modigliani, Franco and Richard Brumberg, "Utility Analysis and the Consumption Function: An Interpretation of Cross-Section Data," in Post-Keynesian Economics, K. Kurihara, ed., New Brunswick, N.J.: Rutgers Univ. Press, 1954.

Muth, John, "Optimal Properties of Exponentially Welghted Forecasts," Journal of the American Statistical Association, 55, June 1960, 299-306.

Nugent, Rolf, Consumer Credit and Economic Stability, New York: Russell Sage Foundation, 1939.

Sargent, Thomas, "Rational Expectations, Econometric Exogeneity, and Consumption," Journal of Political Economy, 86, August 1978, 673-700. 
Stone, Richard and D. A. Rowe, "The Market Demand for Durable Goods," Econometrica, 25, July 1957, 423-43.

Taylor, Lester, "Saving out of Different Types of Income," Brookings Papers on Economic Activity, 1971:2, 383-416.

Tobin, James, "Estimation of Relationships for Limited Dependent Variables," Econometrica, 26, January 1958, 24-36.

U.S. Bureau of Economic Analysis, Survey of Current Business, various issues.

Whalen, Edward, "A Rationalization of the Precautionary Demand for Cash," Quarterly Journal of Economics, 80, May 1966, 314-24.

Williams, Ross, "Demand for Consumer Durables: Stock Adjustment Models and Alternative Specifications of Stock Depletion," Review of Economic Studies, 39, July 1972, 281-96.

Wykoff, Frank, "Capital Depreciation in the Postwar Period: Automobiles," Review of Economics and Statistics, 52, May 1970, 168-72. 